Forschende

Komplementärmedizin una

Klassische Naturheilkunde

Übersichtsarbeiten

Originalarbeit

Falldarstellung

\section{Contents of Next Issues}

Forsch Komplementärmed Klass Naturheilkd 2002;9:72

Behandlung chronischer Bronchitis mit einem Spezialextrakt aus Efeublättern multizentrische Anwendungsbeobachtung mit 1350 Patienten

Hecker, M.; Runkel, F. (Niederdorfelden); Völp, A. (Frankfurt/M.)

Neue Erkentnisse über Prießnitz aus dem unbekannt gebliebenen «Vinzenz Prießnitz'schen Familien-Wasserbuch» von 1847

Rohde, J. (Berlin)

Antiseptische Wirkung eines Dermatikums, das ein Hamamelisdestillat und Harnstoff enthält

Gloor, M. (Karlsruhe); Reichling, J. (Heidelberg); Wasik, B.; Holzgang, H.E. (Zürich)

Ein Beispiel zum Wert nicht-randomisierter klinischer Studien in der Komplementärmedizin

Lüdtke, R. (Essen); Weber, U.; Fischer, I. (Tübingen); Friese, K.-H. (Weil der Stadt), Moeller, H. (Tübingen)

Kongressbericht

Symposium «Unterschiedliche Paradigmen in der Onkologie - Konsequenzen für Forschung und Praxis», 10./11. November 2000, Witten Herdecke

Herrmann, U. (Düsseldorf), Matthiessen, P.F. (Herdecke) 